\title{
Silibinin suppresses bladder cancer cell malignancy and chemoresistance in an NF- $\kappa B$ signal-dependent and signal-independent manner
}

\author{
YI SUN, ZHENFENG GUAN, WENCAI ZHAO, YAZHUO JIANG, \\ QING LI, YONGYI CHENG and YONGGANG XU \\ Department of Urology, Shaanxi Provincial People's Hospital, Xi'an, Shaanxi 710068, P.R. China
}

Received May 3, 2017; Accepted July 26, 2017

DOI: $10.3892 /$ ijo.2017.4089

\begin{abstract}
Because bladder cancer $(\mathrm{BCa})$ is the $9^{\text {th }}$ most common malignant tumor and $13^{\text {th }}$ leading cause of death due to cancer, therapeutic approaches have attracted a great deal of attention from both clinicians and BCa patients. Although the development of surgery and targeted drugs has brought new challenges for the traditional concept of BCa therapy, various types of chemotherapy remain the final treatment method for many BCa patients. However, chemoresistance inevitably appears, leading to the failure of chemotherapy. Silibinin, a polyphenolic flavonoid component isolated from the fruits or seeds of milk thistle, has been reported to play important roles in inhibiting tumor chemoresistance in breast cancer and head and neck squamous cell carcinomas. Our previous study indicated that silibinin inhibited $\mathrm{BCa}$ progression in some mechanisms but with no conclusion of chemoresistance inhibition. Therefore, in the present study, we dissected the role of silibinin in BCa progression and chemoresistance. Our results revealed that in $\mathrm{BCa}$, chemodrug-induced chemoresistance was reversed in the presence of silibinin. Further mechanistic study indicated that silibinin suppressed chemoresistance and BCa malignancy in an NF- $\mathrm{BB}$-dependent and -independent manner. In addition, all of the inhibitory effects were dose-dependent. Thus, our results provide a potential use for silibinin in BCa therapeutics.
\end{abstract}

\section{Introduction}

Worldwide, bladder cancer $(\mathrm{BCa})$ is the $9^{\text {th }}$ most common cancer and the $13^{\text {th }}$ leading cause of death due to cancer (1), and it has attracted increasing attention from clinicians over

Correspondence to: Dr Zhenfeng Guan, Department of Urology, Shaanxi Provincial People's Hospital, 256 Youyi West Road, Xi'an, Shaanxi 710068, P.R. China

E-mail: guanzhenfeng@163.com

Key words: bladder cancer, cisplatin, MDR1, silibinin, NF-кB signal the past several decades. The risk factors for $\mathrm{BCa}$ include but are not limited to genetic predisposition and acquired exposure, the mechanism of which is still unclear (2-5). Clinically, according to the pathological characteristics, BCa includes superficial and invasive types, which are treated using different therapeutic procedures. Briefly, the recommended therapeutic guideline for superficial $\mathrm{BCa}$ is transurethral resection of bladder tumor (TUR-bt), followed by intravesical chemo- or immunotherapeutics. Unfortunately, $70 \%$ of superficial $\mathrm{BCa}$ will inevitably progress to the invasive type followed by enhanced tumor malignancy. For invasive BCa, cystectomy plus adjuvant or neoadjuvant chemotherapy is accepted by clinicians and patients (6). Thus, chemotherapy is a vital and irreplaceable regimen for treating invasive $\mathrm{BCa}$, regardless of whether initial invasive $\mathrm{BCa}$ or invasive $\mathrm{BCa}$ progressed from the superficial type. Many studies have indicated that cisplatin-based regimens play effective roles in $\mathrm{BCa}$ therapy $(7,8)$. However, chemoresistance to cisplatin-containing regimens inevitably appears in the battle against $\mathrm{BCa}$, the mechanism of which is still unknown.

Previous reports have identified the important roles of $\mathrm{NF}-\kappa \mathrm{B}$ signaling in the initiation and progression of $\mathrm{BCa}, \mathrm{e} . \mathrm{g}$., promoting the process of epithelial to mesenchymal transition (EMT) (9), secreting MMP2/MMP9 and inhibiting apoptosis. In addition, the promoter of MDR1 (ABCB1), a multiple drug-resistant gene, contains an NF- $\kappa \mathrm{B}$ binding site, indicating that MDR1 was monitored by this signaling pathway (10).

Silibinin, a polyphenolic flavonoid component isolated from the fruits or seeds of milk thistle (Silybum marianum), has been clinically used to treat various diseases, and it has been suggested that this reagent exhibited protective effects for patients with liver or heart disease. The inhibitory effects of silibinin against cancer were also indicated (11-17) in tumors such as breast cancer and head and neck squamous cell carcinomas. Our previous study indicated that silibinin inhibited BCa progression (18), leading us to hypothesize a link between silibinin and $\mathrm{BCa}$ chemoresistance.

In the present study, we hypothesized that silibinin may play inhibitory roles in the chemoresistance of BCa cells, possibly involving the NF- $\mathrm{B}$ signaling pathway. Our results revealed that silibinin inhibited the progression and reversed the chemoresistance of $\mathrm{BCa}$ cells in an NF- $\mathrm{B}$-dependent and 
-independent manner, thus providing a potential therapeutic use for silibinin in patients with $\mathrm{BCa}$.

\section{Materials and methods}

Cell culture. Human BCa cell lines T24 and J82 were obtained from the ATCC (American Type Culture Collection, Manassas, VA, USA) and cultured in DMEM supplemented by $10 \%$ FBS (Invitrogen, Carlsbad, CA, USA). Cells were cultured in incubators (Thermo Scientific, Germany) in an atmosphere with $5 \% \mathrm{CO}_{2}$ at $37^{\circ} \mathrm{C}$.

To obtain stable, cisplatin-resistant cell lines, we monitored the $\mathrm{IC}_{50}$ of cisplatin and obtained values of $58 \mu \mathrm{M}$ for $\mathrm{T} 24$ and $49 \mu \mathrm{M}$ for J82. Second, the cisplatin-resistant index (RI) was evaluated by MTT; the RIs of the cell lines were 21.35 and 28.75 for T24 and J82, respectively. The cultured parental T24 and J82 cells were supplemented with $20 \mu \mathrm{M}$ cisplatin. The medium was refreshed every two days to remove the dead cells, and the cells were washed three times with sterile PBS (pH 7.2). This treatment was administered for more than three months to obtain stable cisplatin-resistant T24/J82 cells (tagged with $\mathrm{T} 24^{\mathrm{R}} / \mathrm{J} 82^{\mathrm{R}}$ ).

To inhibit NF- $\kappa \mathrm{B}$ signaling, pyrrolidine dithiocarbamate (PDTC) (Sigma-Aldrich, USA) (19), an inhibitor of the NF- $\mathrm{B}$ pathway, was used; the final concentration was $10 \mu \mathrm{M}$ in the medium for the last $24 \mathrm{~h}$ before analysis.

Wound healing assay. Wound healing assays were carried out by scratching a 6 -well dish with a $10-\mu 1$ pipette tip when the dish was at $80 \%$ confluence (including parental cell and cisplatin-resistant cell lines). The width of the scratches was compared at $0,6,12$ and $24 \mathrm{~h}$ after scratching.

Western blot analysis. Pretreated cells were harvested at $80 \%$ confluency and washed three times with cold PBS. Total cellular protein lysates were prepared with RIPA buffer [50 mM Tris (pH 8.0), $150 \mathrm{mM} \mathrm{NaCl}, 0.1 \%$ SDS, $1 \%$ NP40 and $0.5 \%$ sodium deoxycholate] containing proteinase inhibitors [1\% inhibitor cocktail and $1 \mathrm{mM}$ PMSF, both from Sigma, (St. Louis, MO, USA)]. Then, $30 \mu \mathrm{g}$ of protein was separated on $10 \%$ SDS-PAGE gels and transferred to nitrocellulose membranes. The membranes were blocked at room temperature for $1 \mathrm{~h}$ with 5\% skim milk in Tris-buffered saline (pH 7.6, TBS). Polyclonal primary antibodies were applied at different dilutions (Table I) in 5\% skim milk in TBS at $4^{\circ} \mathrm{C}$ overnight, followed by TBST (with Tween-20) washes. Membranes were incubated with fluorescent secondary antibodies (LI-COR, Rockford, IL, USA) coupled to the first antibody at room temperature in the dark for $1 \mathrm{~h}$, then washed with TBST, dried with neutral absorbent paper and scanned with the Odyssey Detection system (LI-COR). MG-132 (Sigma-Aldrich) was used to inhibit the proteasomedependent degradation when necessary $(10 \mu \mathrm{M}, 4 \mathrm{~h}$ before the protein harvest). GAPDH was used as a loading control (for total cell fraction).

Real-time PCR. Cellular total RNA was isolated using TRIzol reagent (Invitrogen) and quantified by absorbance at $260 \mathrm{~nm}$. RNA $(2 \mu \mathrm{g})$ was reverse transcribed using Revert Aid ${ }^{\mathrm{TM}}$ First Strand cDNA Synthesis kit (MBI Fermentas, St. Leon-Rot,
Table I. Information on the antibodies.

\begin{tabular}{lllll}
\hline Gene ID & Antibody & Dilutions & Species & Supplied by \\
\hline NM_004360.3 & E-cadherin & $1: 600$ & Homo & Santa Cruz \\
NM_001792.3 & N-cadherin & $1: 300$ & Homo & Santa Cruz \\
NM_003380.3 & Vimentin & $1: 300$ & Homo & Santa Cruz \\
NM_004530.4 & MMP2 & $1: 400$ & Homo & Santa Cruz \\
NM_004994.2 & MMP9 & $1: 400$ & Homo & Santa Cruz \\
NM_002046.4 & GAPDH & $1: 15,000$ & Homo & Abcam \\
NM_000927.4 & ABCB1 & $1: 400$ & Homo & Santa Cruz \\
& $\beta$-actin & $1: 300$ & Homo & Santa Cruz
\end{tabular}

Germany) strictly according to the manufacturer's protocol. For real-time PCR, we used the SYBR Premix Ex Taq ${ }^{\mathrm{TM}}$ II system (Takara Biotechnology Co., Ltd., Dalian, China) and the Bio-Rad CFX96TM Real-time system (Bio-Rad, CA, USA). Primers are listed in Table II. Briefly, $12.5 \mu \mathrm{l}$ of SYBR Premix Ex Taq II, $1 \mu \mathrm{l}$ of primer (F and R, respectively), $200 \mathrm{ng}$ of cDNA and $9.5 \mu \mathrm{l}$ of distilled and deionized water were mixed together, followed by two-stage, pre-denaturation at $95^{\circ} \mathrm{C}$, $30 \mathrm{sec}$, one repeat; and $\mathrm{PCR}$ reaction, at $95^{\circ} \mathrm{C}, 5 \mathrm{sec}$ followed by $60^{\circ} \mathrm{C}, 30 \mathrm{sec}, 30$ repeats; and the third stage as dissociation, $95^{\circ} \mathrm{C}, 15 \mathrm{sec}$ followed by $60^{\circ} \mathrm{C}, 30 \mathrm{sec}$, and another $95^{\circ} \mathrm{C}$, $15 \mathrm{sec}$. GAPDH was used as the loading control.

Cell viability assay (MTT assay). Cell viability was assessed using a tetrazolium-based assay. Pretreated cells were incubated in the absence or presence of cisplatin/doxorubicin for the indicated times, and then washed once with PBS and incubated with $0.5 \mathrm{mg} / \mathrm{ml}$ of MTT at $37^{\circ} \mathrm{C}$ for $1 \mathrm{~h}$. The reagent was reduced by living cells to form an insoluble blue formazan product. After incubation, cells were lysed with DMSO. Colorimetric analysis using a 96-well microplate reader was performed at a wavelength of $490 \mathrm{~nm}$. The experiments were performed in triplicate.

Cell migration/invasion assay. Migration/invasion ability was demonstrated by Boyden chamber assay. Chambers with $8-\mu \mathrm{m}$-diameter pores were obtained from Millipore (Millipore, Switzerland). For the migration assay, $0.2 \mathrm{ml}$ of FBS-free DMEM medium suspension with 10,000 cells was added to the upper chamber in a 24-well plate, and $0.8 \mathrm{ml}$ of FBS-free DMEM was added to the lower chamber. After $12 \mathrm{~h}$ of incubation, the chambers were washed with PBS ( $\mathrm{pH} \mathrm{7.4)}$ three times to remove the cells in the upper chamber, fixed with $4 \%$ formalin for $15 \mathrm{~min}$, and then stained with crystal violet $(0.01 \%$ in ethanol) for $25 \mathrm{~min}$ followed by washing three times with PBS. The cells were counted using an inverted microscope, five images were randomly taken at 200x magnification, and the average number of cells was analyzed. For the invasion assay, the cell suspension (10,000 cells/well) in the upper chamber contained $0.2 \mathrm{ml}$ mixture of FBS-free DMEM/Matrigel at an 8/1 ratio (Matrigel, Sigma, USA). Cells were incubated for $36 \mathrm{~h}$, and the remainder of the protocol was conducted in a similar manner to the migration assay. 
Table II. Primers for real-time PCR.

\begin{tabular}{|c|c|c|}
\hline Gene ID & Gene & Primers \\
\hline NM_002046.4 & $G A P D H$ & $\begin{array}{l}\text { F: AAC AGC GAC ACC CAT CCT C } \\
\text { R: CAT ACC AGG AAA TGA GCT TGA CAA }\end{array}$ \\
\hline NM_004360.3 & E-cadherin & $\begin{array}{l}\text { F: TGC CCA GAA AAT GAA AAA GG } \\
\text { R: GTG TAT GTG GCA ATG CGT TC }\end{array}$ \\
\hline NM_001792.3 & $N$-cadherin & $\begin{array}{l}\text { F: ACA GTG GCC ACC TAC AAA GG } \\
\text { R: CCG AGA TGG GGT TGA TAA TG }\end{array}$ \\
\hline NM_003380.3 & Vimentin & $\begin{array}{l}\text { F: GAG AAC TTT GCC GTT GAA GC } \\
\text { R: GCT TCC TGT AGG TGG CAA TC }\end{array}$ \\
\hline NM_004530.4 & $M M P 2$ & $\begin{array}{l}\text { F: CTC ATC GCA GAT GCC TGG AA } \\
\text { R: TTC AGG TAA TAG GCA CCC TTG AAG A }\end{array}$ \\
\hline NM_004994.2 & $M M P 9$ & $\begin{array}{l}\text { F: TGA CAG CGA CAA GAA GTG } \\
\text { R: CAG TGA AGC GGT ACA TAG G }\end{array}$ \\
\hline NM_000927.4 & $A B C B 1$ & $\begin{array}{l}\text { F: GTC CCA GGA GCC CAT CCT } \\
\text { R: CCC GGC TGT TGT CTC CAT A }\end{array}$ \\
\hline
\end{tabular}

Cell proliferative capacity assay. A 5-bromo-2-deoxyuridine (BrdU) incorporation assay was used to analyze tumor proliferative ability. Briefly, pretreated cells were plated on 8-well glass plates (Millipore) until 50-70\% confluency. BrdU was added to the medium ( $3 \mu \mathrm{g} / \mathrm{ml}$ ), followed by $4 \mathrm{~h}$ of incubation and rinsing $3 \mathrm{X}$ with PBS over $10 \mathrm{~min}$ to remove residual free BrdU. Cells were then fixed with $4 \%$ paraformaldehyde for $45 \mathrm{~min}$, followed by rinsing $5 \mathrm{X}$ with PBS over $20 \mathrm{~min}$. Then, $0.1 \%$ Triton $\mathrm{X}-100$ was used to permeabilize the cell membrane for $15 \mathrm{~min}$, and $2 \mathrm{~N} \mathrm{HCl}$ was added for $25 \mathrm{~min}$ to separate DNA into single strands and thus allowing primary antibody access to the incorporated BrdU. Cells were then rinsed $3 \mathrm{X}$ with $\mathrm{PBS}$ over $10 \mathrm{~min}$, and non-specific epitopes were blocked by $10 \%$ BSA for $20 \mathrm{~min}$. Anti-BrdU antibody (1:200) in 10\% BSA was added and incubated overnight at $4^{\circ} \mathrm{C}$. Cells were rinsed $5 \mathrm{X}$ with $\mathrm{PBS}$, followed by incubation with TRITC-labeled secondary antibody for $1 \mathrm{~h}$ at room temperature, and finally rinsed $3 \mathrm{X}$ with PBS to remove the free antibody. The fluorescence intensity of TRITC was monitored with a SuperMicro Orifice Plate spectrophotometer (BioTek, USA) at $547 \mathrm{~nm}$.

Immunofluorescence staining for nuclear translocation of $N F-\kappa B$. After the designated treatment, the pretreated cells were washed three times with cold PBS ( $\mathrm{pH} 7.4$ ), followed by fixing with $4 \%$ paraformaldehyde for $15 \mathrm{~min}$, permeabilization in $0.5 \%$ Triton X-100 for $10 \mathrm{~min}$, and incubation in $1 \%$ BSA blocking solution for $1 \mathrm{~h}$. Fixed cells were incubated overnight at $4^{\circ} \mathrm{C}$ with rabbit anti-human-P65 in 1\% BSA. Cells were washed and incubated with mouse anti-rabbit TRITC (Red) IgG antibody (Santa Cruz Biotechnology, USA) diluted 1:100 in blocking buffer for $1 \mathrm{~h}$. Nuclei were stained with DAPI for $5 \mathrm{~min}$. Cells were examined with a fluorescence microscope equipped with narrow bandpass excitation filters to individually select for red and blue fluorescence. Cells were observed through the Image-Pro Plus system ${ }^{\mathrm{TM}}$ mounted on a fluorescent microscope (Olympus, Japan). Each experiment was repeated three times.

Statistical analysis. ANOVA test was used to analyze the statistical discrepancy in $>3$ groups. Student's t-test was used to detect any statistically significant difference between 2 groups. P-values $<0.05$ were considered significant.

\section{Results}

Stable chemoresistant cell lines induced by cisplatin manifest enhanced migration/invasion and proliferation capacity. Chemoresistance is considered a vital obstacle in the battle against BCa and leads to the failure of BCa chemotherapy (20). Cisplatin, which is one of the major reagents in the chemotherapeutic regime for $\mathrm{BCa}$, is recommended as first-line treatment in the clinic (21). Therefore, cisplatin resistance is ubiquitous in BCa patients, and dissecting the underlying mechanism potentially brings benefits to $\mathrm{BCa}$ patients. Cisplatin was used to treat BCa cell lines T24/J82 to obtain stable cisplatinresistant cell lines (tagged by $\mathrm{T} 24^{\mathrm{R}}$ and $\mathrm{J} 82^{\mathrm{R}}$, respectively), as indicated in the Materials and methods. Compared with parental $\mathrm{T} 24 / \mathrm{J} 82, \mathrm{~T} 24^{\mathrm{R}} / \mathrm{J} 82^{\mathrm{R}}$ manifested cisplatin-resistance demonstrated by MTT assay (Fig. 1A). In addition, the in vitro analysis suggested that the wound-healing time was shorter for these cisplatin-resistant BCa cells (Fig. 1B), accompanied by enhanced proliferation (Fig. 1C) and migration /invasion (Fig. 1E) ability.

EMT markers are induced in $T 24^{R} / J 82^{R}$ cells, accompanied by elevated expression of $A B C B 1$ (MDR1). The enhanced capacity of migration/invasion and proliferation of $\mathrm{T} 24^{\mathrm{R}} / \mathrm{J} 82^{\mathrm{R}}$ prompted us to monitor the expression of related genes, including EMT markers and matrix metalloproteinase (MMP). Both western blot analysis (Fig. 2A) and real-time PCR (Fig. 2B) indicated the elevated expression of 

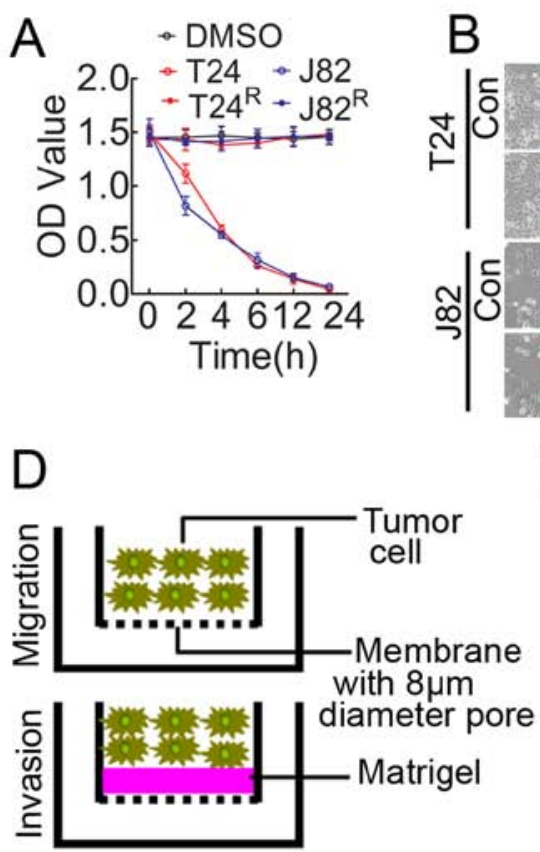

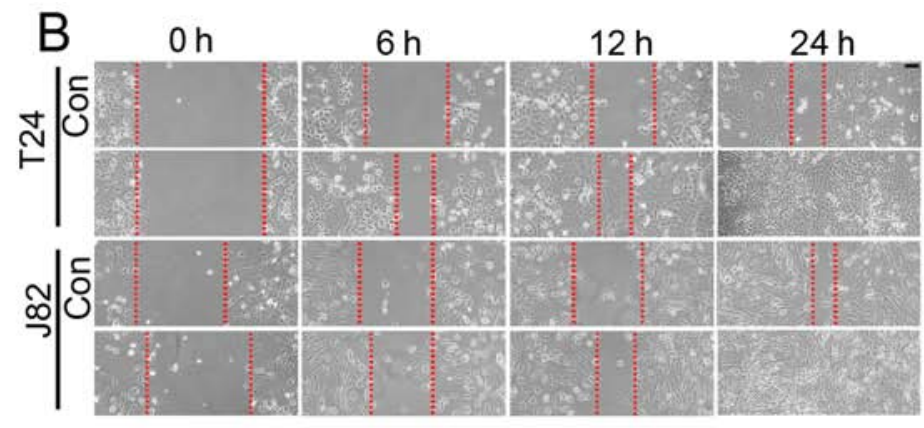

B $0 \mathrm{~h}$

E

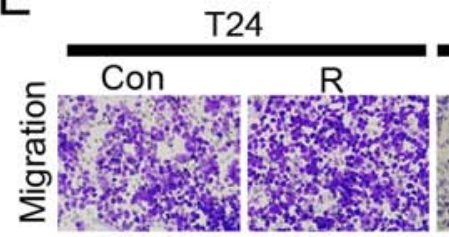

$\mathrm{J} 82$
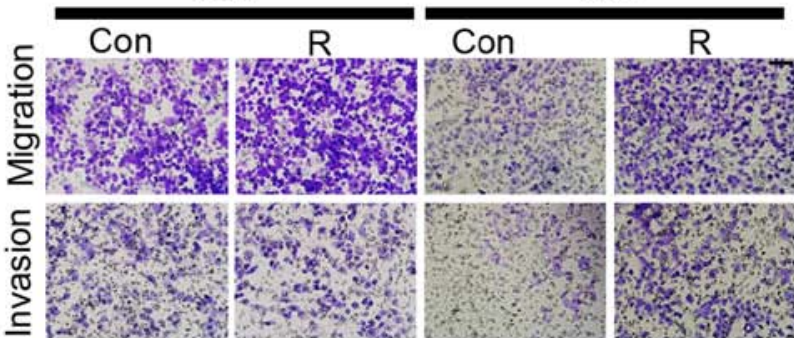
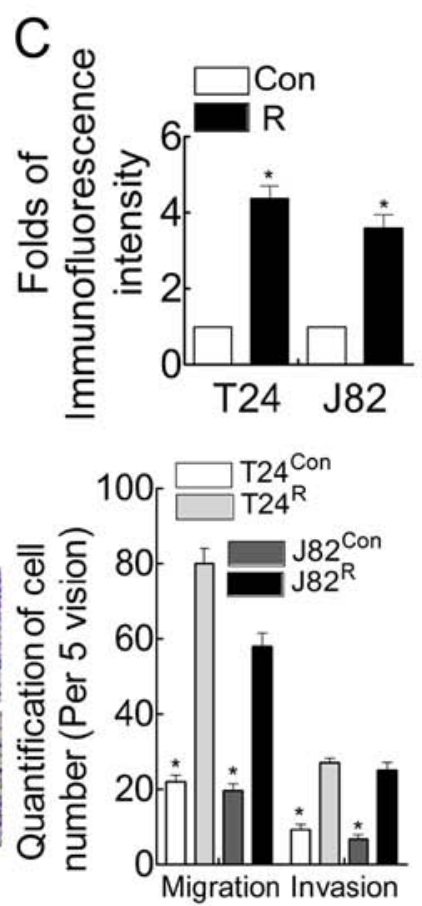

Figure 1. Cisplatin-resistant BCa cell lines T24/J82 manifest enhanced migration/invasion and proliferation capacities. (A) MTT assay showed that compared with parental $\mathrm{T} 24 / \mathrm{J} 82$, cisplatin-resistant $\mathrm{T} 24 / \mathrm{J} 82\left(\mathrm{~T} 24^{\mathrm{R}} / \mathrm{J} 82^{\mathrm{R}}\right)$ manifested enhanced cisplatin-resistant capacity. (B) Wound healing assay indicated that $\mathrm{T} 24^{\mathrm{R}} /$ $\mathrm{J}^{2} 2^{\mathrm{R}}$ exhibited shorter wound healing times comparing with parental T24/J82; bar, $100 \mu \mathrm{m}$. (C) Quantification of BrdU incorporation suggested that the proliferation capacity of $\mathrm{T} 24^{\mathrm{R}} / \mathrm{J} 82^{\mathrm{R}}$ was enhanced almost 4 -fold relative to parental T24/J82; ${ }^{*} \mathrm{P}<0.05$. (D) Cartoon of Boyden chamber assay. (E) Boyden chamber assay suggested the increased migration/invasion ability of $\mathrm{T} 24^{\mathrm{R}} / \mathrm{J} 82^{\mathrm{R}}$ compared with $\mathrm{T} 24 / \mathrm{J} 82$. Left, representative figures; bar, $100 \mu \mathrm{m}$. Right, quantification of the Boyden chamber assay; ${ }^{*} \mathrm{P}<0.05$.
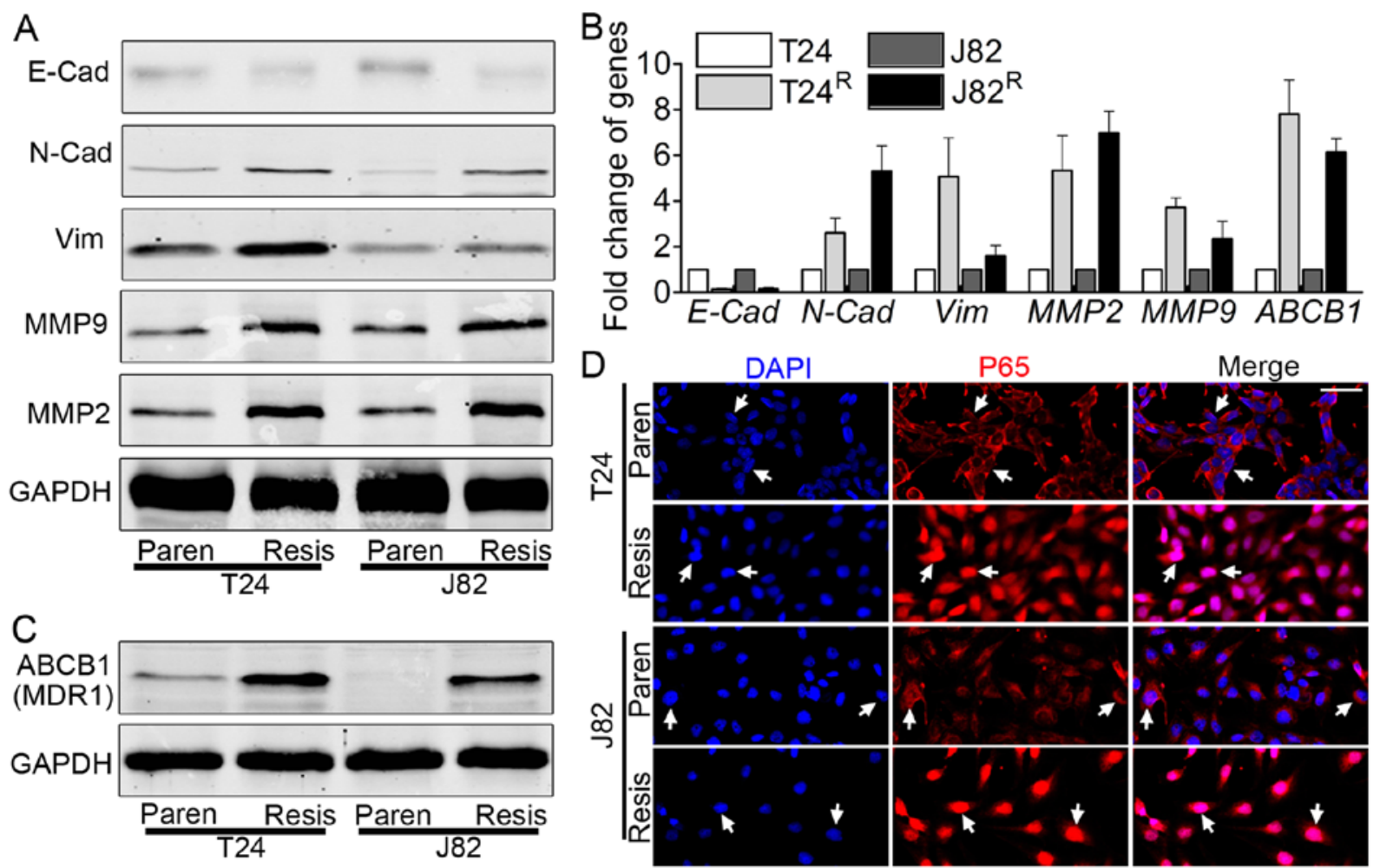

Figure 2. Epithelial to mesenchymal transition (EMT) is enhanced in $\mathrm{T} 24^{\mathrm{R}} / \mathrm{J} 82^{\mathrm{R}}$ cells, accompanied by increased expression of $A B C B 1$ and NF- $\mathrm{KB}$ nuclear translocation. (A) Western blot analysis showed elevated expression of N-cadherin, vimentin, MMP2 and MMP9 but decreased expression of E-cadherin in $\mathrm{T} 24^{\mathrm{R}} / \mathrm{J} 82^{\mathrm{R}}$ vs $\mathrm{T} 24 / \mathrm{J} 82$, indicating the process of EMT. (B) Real-time PCR results were consistent with western blot analysis results, including elevated expression of N-cadherin, vimentin, MMP2 and MMP9 but decreased E-cadherin. In addition, the expression of ABCB1, the multiple drug-resistant gene, was also elevated in $T 24^{\mathrm{R}} / \mathrm{J} 82^{\mathrm{R}}$ vs T24/J82. (C) Western blot analysis suggested that the expression of the multiple drug-resistant gene, ABCB1, and also MDR1, was elevated as expected in $\mathrm{T} 24^{\mathrm{R}} / \mathrm{J} 82^{\mathrm{R}}$. (D) Immunofluorescence staining revealed the nuclear translocation of NF- $\mathrm{kB}(\mathrm{P} 65)$ in $\mathrm{T} 24^{\mathrm{R}} / \mathrm{J} 82^{\mathrm{R}}$, as the white arrow indicates; bar, $100 \mu \mathrm{m}$. Paren=Parental; Resis=Resistant. 

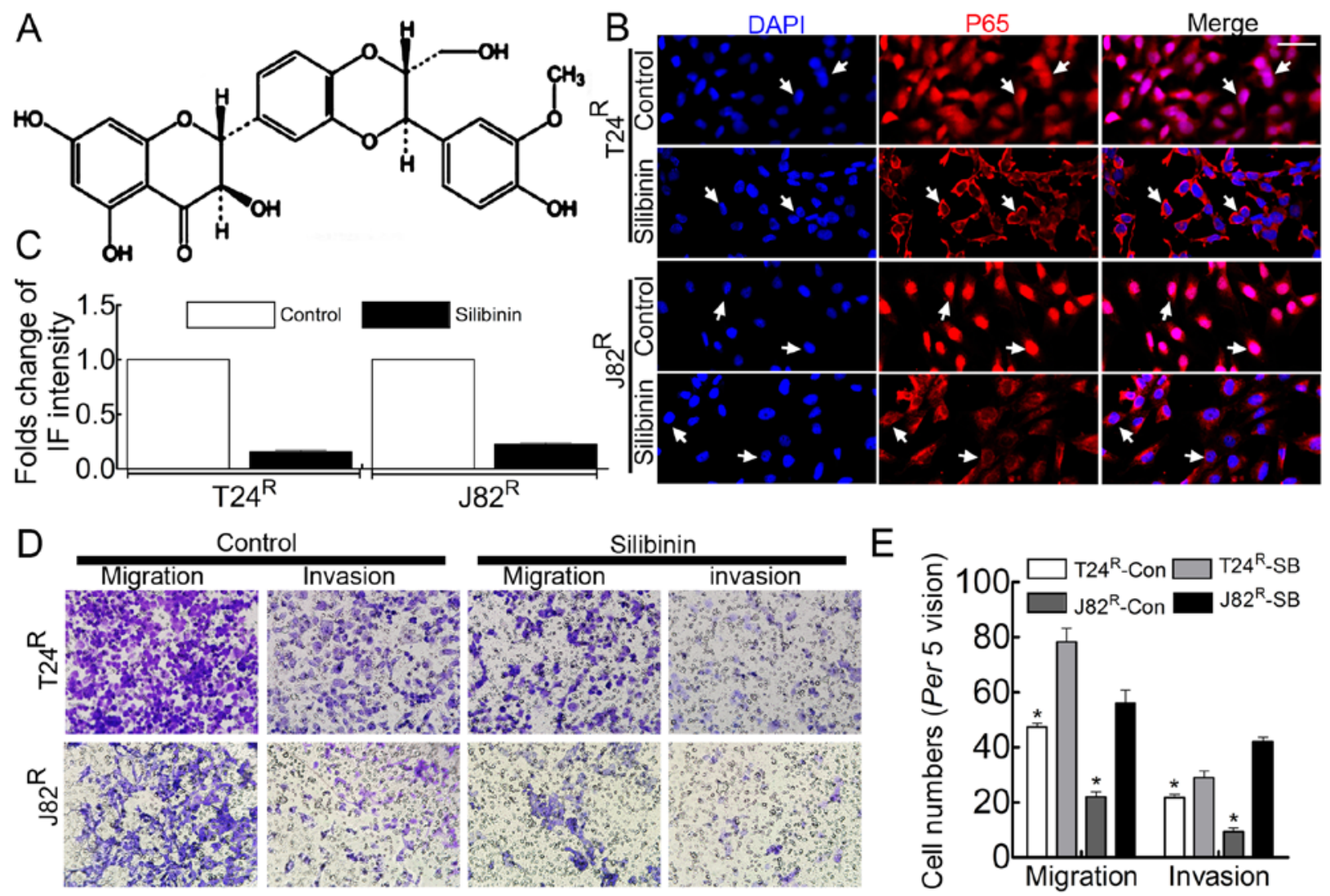

Figure 3. The malignant behavior of $\mathrm{T} 24^{\mathrm{R}} / \mathrm{J} 82^{\mathrm{R}}$ is inhibited by silibinin (SB). (A) The chemical structure of silibinin. (B) Immunofluorescence staining suggested that the nuclear translocation of NF- $\kappa \mathrm{B}$ can be inhibited by silibinin, as indicated by white arrows; bar, $100 \mu \mathrm{m}$. (C) Quantification of BrdU incorporation revealed that the proliferation capacity of $\mathrm{T} 24^{\mathrm{R}} / \mathrm{J} 82^{\mathrm{R}}$ was attenuated in the presence of silibinin. (D) Representative images of the Boyden chamber assay suggested that compared with the control, silibinin significantly inhibited the malignant behavior of T2 $4^{\mathrm{R}} / \mathrm{J} 82^{\mathrm{R}}$; bar, $100 \mu \mathrm{m}$. (E) Quantification of the Boyden chamber assay, indicating the attenuated migration/invasion capacity of $\mathrm{T} 24^{\mathrm{R}} / \mathrm{J} 82^{\mathrm{R}}$ in the presence of silibinin; ${ }^{*} \mathrm{P}<0.05$.

EMT-related markers, e.g., N-cadherin, vimentin, MMP2 and MMP9, with decreased expression of E-cadherin. ABCB1, also called MDR1, plays a vital role in BCa chemoresistance (20). Therefore, the expression of ABCB1 was monitored in $\mathrm{T} 24^{\mathrm{R}} / \mathrm{J} 82^{\mathrm{R}}$ by western blot analysis and real-time PCR. ABCB1 was elevated in $\mathrm{T} 24^{\mathrm{R}} / \mathrm{J} 82^{\mathrm{R}}$ vs. T24/J82, as shown by blot analysis (Fig. 2C) and real-time PCR (Fig. 2B).

$N F-\kappa B$ signaling is overactivated in $T 24^{R} / J 82^{R}$. Emerging evidence noted the importance of $N F-\kappa B$ signaling in tumorigenesis and cancer metastasis $(22,23)$, as well as chemoresistance (24), leading us to link the cisplatininduced phenomenon to this signaling pathway. As indicated in Fig. 2D, immunofluorescence staining suggested that $\mathrm{T} 24^{\mathrm{R}} / \mathrm{J} 82^{\mathrm{R}}$ cells significantly manifested P65 nuclear translocation, suggesting the activation of this signaling pathway. In a parallel experiment, nuclear lysates from $\mathrm{T} 24^{\mathrm{R}} / \mathrm{J} 82^{\mathrm{R}}$ indicated the accumulation of P65 in nuclei, as demonstrated by blot analysis (data not shown). Thus, we concluded that NF- $\mathrm{B}$ signaling was overactivated in $\mathrm{T} 24^{\mathrm{R}} / \mathrm{J} 82^{\mathrm{R}}$ cells vs. parental T24/J82 cells.

Migration/invasion ability and proliferation of $T 24^{R} / J 82^{R}$ are attenuated in the present of silibinin, accompanied by inhibition of $N F-\kappa B$ signaling in $T 24^{R} / J 82^{R}$ cells. Silibinin has been used clinically to treat various liver diseases and has been marketed as a dietary supplement (25). Previous studies had noted that silibinin inhibited tumor growth by suppressing MMPs $(26,27)$, VEGF, HIF-1 $\alpha$ (25) and the process of EMT $(28,29)$. In the present study, silibinin was used to treat BCa cell T24 ${ }^{\mathrm{R}} / \mathrm{J} 82^{\mathrm{R}}$, followed by Boyden chamber assay, BrdU incorporation and immunofluorescence staining to observe the malignant behavior. As expected, the enhanced proliferation capacity of $\mathrm{T} 24^{\mathrm{R}} / \mathrm{J} 82^{\mathrm{R}}$ cells was attenuated in the presence of $100 \mu \mathrm{M}$ silibinin (Fig. 3B), accompanied by decreased migration/invasion ability (Fig. 3C and E). In addition, the nuclear translocation of NF- $\kappa \mathrm{B}$ was significantly inhibited in the presence of silibinin in $\mathrm{T} 24^{\mathrm{R}} / \mathrm{J} 82^{\mathrm{R}}$ cells (Fig. 3D).

Silibinin suppresses the migration/invasion and proliferation capacity of $T 24^{R} / J 82^{R}$ cells by inhibiting the expression of EMT-related markers and ABCBI in a dose-dependent manner. Previous results suggested that silibinin could inhibit cisplatin-induced migration/invasion and proliferation. In addition, immunofluorescence staining indicated that silibinin could inhibit the activity of the NF- $\kappa \mathrm{B}$ signaling pathway. According to the previous studies, this phenomenon was accompanied by an alteration of related genes and might be involved in a related signaling pathway. Therefore, we monitored the expression of EMT-related markers and $\mathrm{ABCB} 1$ in the presence of silibinin. As indicated in Fig. 4A and $B$, silibinin treatment led to significant inhibition of EMT, e.g., decreased expression of vimentin, N-cadherin, MMP2, and MMP9, with increased E-cadherin expression. 

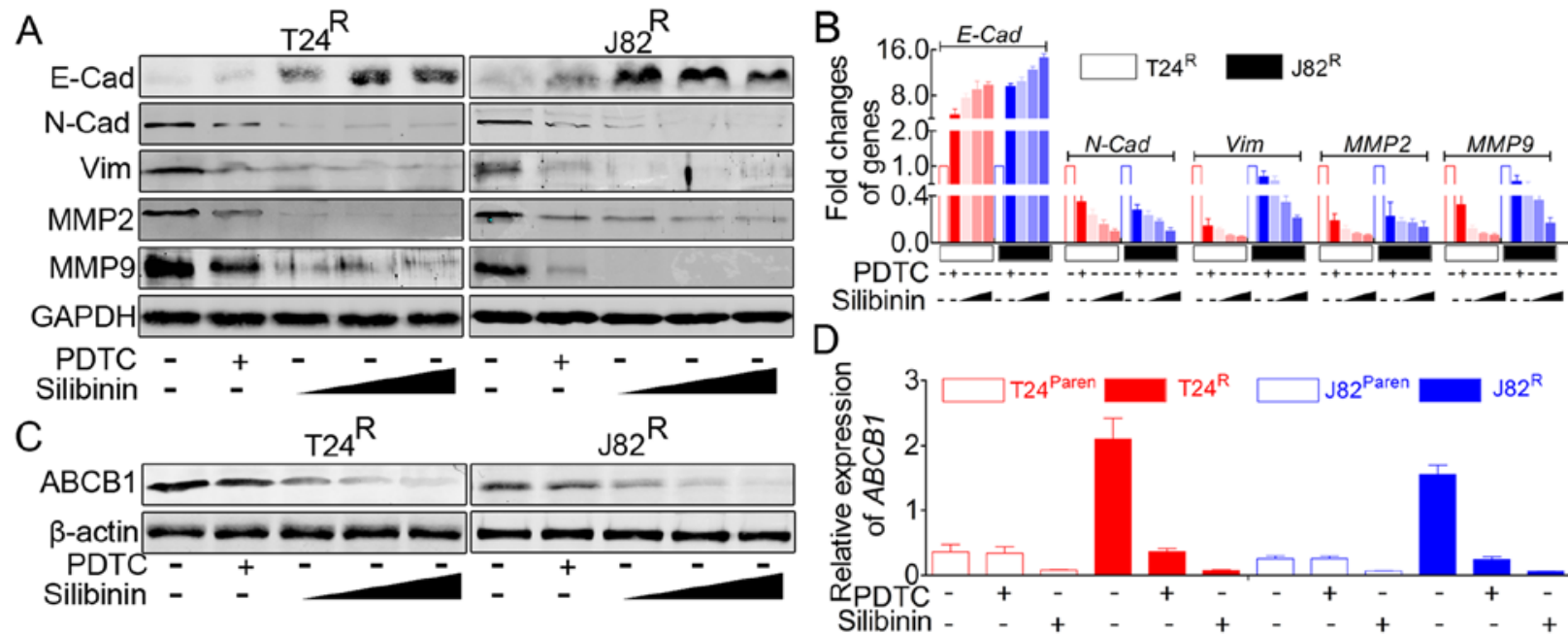

Figure 4. Silibinin inhibits $\mathrm{T} 24^{\mathrm{R}} / \mathrm{J} 82^{\mathrm{R}}$ malignancy in an NF- $\mathrm{kB}$-dependent and -independent manner, accompanied by attenuating the expression of ABCB1. (A) Western blot analysis suggested that PDTC, a classical inhibitor of NF-kB signaling, partially inhibited EMT, e.g., elevated expression of E-cadherin accompanied by decreased expression of N-cadherin, vimentin, MMP2 and MMP9; in addition, silibinin led to the reversal of EMT in a dose-dependent manner. (B) Real-time PCR indicated that the inhibition of NF- $\mathrm{KB}$ signaling by PDTC led to the reversal of EMT markers in T24 ${ }^{\mathrm{R}} / \mathrm{J} 82^{\mathrm{R}}$, and this EMT reversal can be enhanced by silibinin in a dose-dependent manner. (C) Western blot analysis showed that both PDTC and silibinin resulted in the decreased expression of ABCB1 but that silibinin possessed more powerful roles in a dose-dependent manner. (D) Real-time PCR revealed that PDTC could lead to the attenuation of $\mathrm{ABCB} 1$ in $\mathrm{T} 24^{\mathrm{R}} / \mathrm{J} 82^{\mathrm{R}}$ but had no visible effects on parental $\mathrm{T} 24 / \mathrm{J} 82$, whereas silibinin significantly inhibited the expression of $\mathrm{ABCB} 1$ in both cisplatin-resistant and parental T24/J82 cells.
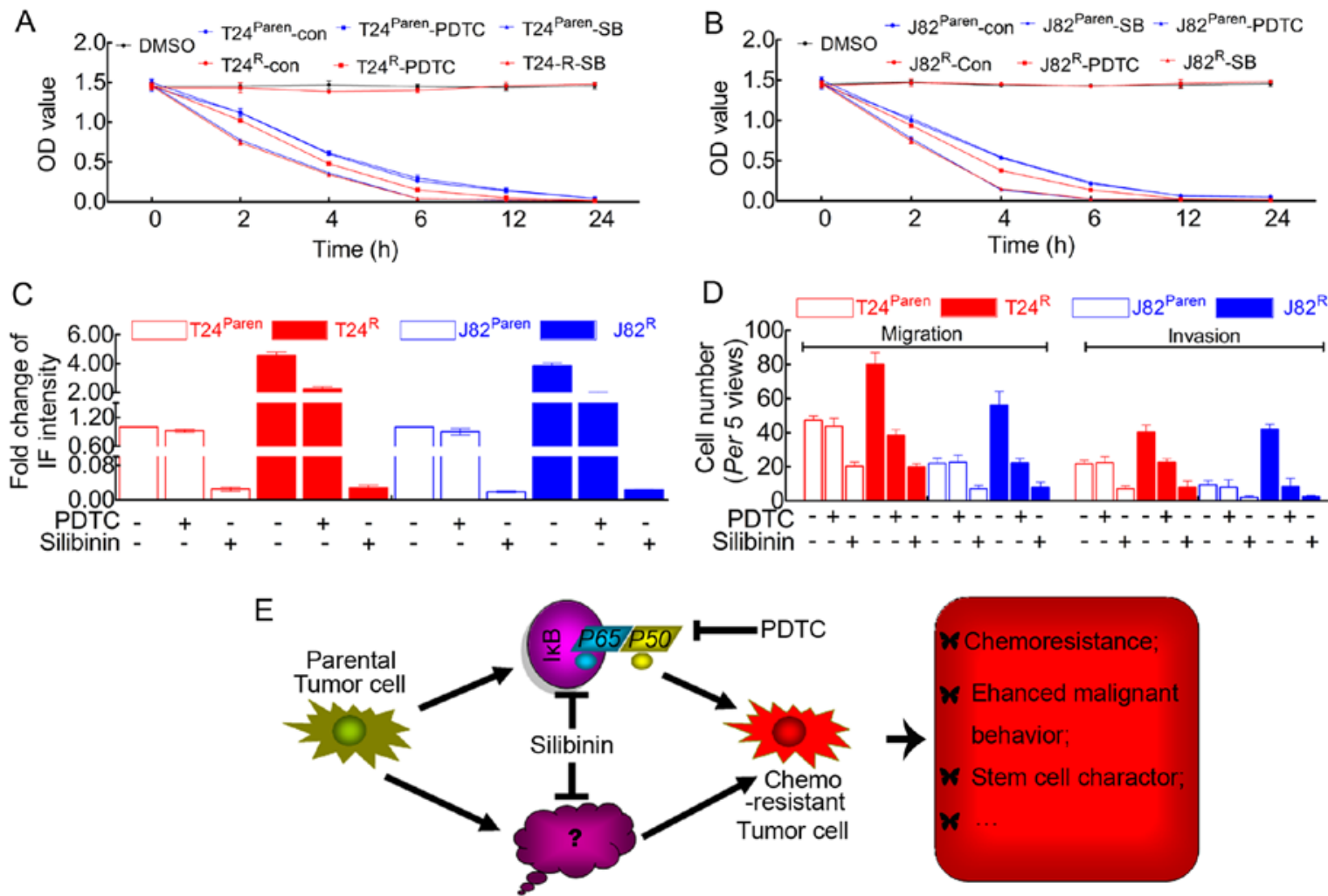

Figure 5. Silibinin exhibits more powerful roles in inhibiting cisplatin resistance, cell proliferation and migration/invasion. (A) MTT assay revealed that the cisplatin resistance of $\mathrm{T} 24^{\mathrm{R}}$ was destroyed in the presence of silibinin. Silibinin induced the enhanced cisplatin sensitivity of parental T24. In addition, PDTC attenuated the cisplatin resistance of T24 $4^{\mathrm{R}}$ but had no visible effect on parental T24. (B) MTT assay revealed that the cisplatin resistance of J82R was destroyed in the presence of silibinin. Silibinin induced the enhanced cisplatin sensitivity of parental J82. In addition, PDTC attenuated the cisplatin resistance of J82R but had no visible effect on parental J82. (C) Quantification of BrdU incorporation suggested that silibinin possessed more powerful effects on inhibiting BCa cell proliferation in both cisplatin-resistant cell lines and parental cell lines. However, PDTC seemed to have little effect on parental T24/J82, although the proliferative capacity of $\mathrm{T} 24^{\mathrm{R}} / \mathrm{J} 82^{\mathrm{R}}$ was inhibited by this reagent. (D) Quantification of the Boyden chamber assay suggested that silibinin significantly attenuated the migration/invasion capacity of both parental and cisplatin-resistant T24/J82 cells. In addition, malignancy of T2 $24^{\mathrm{R}} / \mathrm{J} 82^{\mathrm{R}}$ but not parental T24/J82 was inhibited by PDTC. (E) In summary: The prolonged time of cisplatin treatment inevitably resulted in drug resistance, the mechanism of which included but was not limited to the activation of NF- $\kappa B$ signaling, leading to the failure of chemotherapeutics. Like PDTC, silibinin was able to inhibit NF- $\kappa B$ signaling, which reversed the malignant behavior of drug-resistant cell lines. However, silibinin also attenuated chemoresistance and tumor cell malignancy in an NF-kBindependent manner, which is still unknown [tagged by ? in (E)]. 
In addition, silibinin suppressed the expression of ABCB1 in T2 $4^{\mathrm{R}} / \mathrm{J} 82^{\mathrm{R}}$ (Fig. 4C and D). As indicated in Fig. 4, the effects of silibinin on $\mathrm{T} 24^{\mathrm{R}} / \mathrm{J} 82^{\mathrm{R}}$ manifested in a dose-dependent manner, at doses from $100 \mu \mathrm{M}, 200 \mu \mathrm{M}$ to $400 \mu \mathrm{M}$, but revealed the most powerful role of PDTC.

Forced inhibition of $N F-\kappa B$ signaling in $T 24^{R} / J 82^{R}$ also leads to decreased expression of EMT-related markers and $A B C B 1$. Previous reports indicated that forced inhibition of $\mathrm{NF}-\kappa \mathrm{B}$ signaling in $\mathrm{BCa}$ cells resulted in the reversal of EMT (30). Herein, in parallel, we used a specific inhibitor of $\mathrm{NF}-\kappa \mathrm{B}$ signal to repeat this process. In accordance with previous reports, our data indicated that PDTC effectively attenuated the activation of NF- $\kappa \mathrm{B}$ signaling (data not shown), accompanied by decreased expression of EMT-related markers (Fig. 4A and B). In addition, as mentioned above, $\mathrm{ABCB} 1$ was one of the target genes of $\mathrm{NF}-\kappa \mathrm{B}$ signaling, and inhibiting this pathway led to the decreased expression of ABCB1 (Fig. 4C and D).

The suppressive roles of silibinin on $T 24^{R} / J 82^{R}$ cells presented $N F-\kappa B$-dependent and-independent mechanisms. The previous results suggested that silibinin manifested more powerful inhibitory roles on $\mathrm{T} 24^{\mathrm{R}} / \mathrm{J} 82^{\mathrm{R}}$ cells than on parental T24/J82 cells. Moreover, as stated above, NF- $\kappa \mathrm{B}$ signaling was inactivated in parental T24/J82 cells, suggesting that PDTC had no visible inhibitory roles on the malignancy and proliferative capacity of parental T24/J82 cells. This led us to ask whether the inhibitory roles of silibinin on $T 24^{\mathrm{R}} / \mathrm{J} 82^{\mathrm{R}}$ involved $\mathrm{NF}-\kappa \mathrm{B}$ signaling or whether they were unrelated phenomena. Our results suggested that in $\mathrm{T} 24^{\mathrm{R}} / \mathrm{J} 82^{\mathrm{R}}$ cells, silibinin had a stronger inhibitory role than did PDTC in the tumor cell expression of EMT markers (Fig. 4A and B), ABCB1 (Fig. 4C), cisplatin sensitivity (Fig. 5A and B), proliferation capacity (Fig. 5C) and migration/invasion capacity (Fig. 5D), suggesting that the inhibitory roles of silibinin were partially independent of $N F-\kappa B$ signaling. Combined with the $\mathrm{NF}-\kappa \mathrm{B}$ signal inhibition induced by silibinin, we concluded that silibinin suppressed BCa cell line $\mathrm{T} 24^{\mathrm{R}} / \mathrm{J} 82^{\mathrm{R}}$ in an NF- $\kappa \mathrm{B}$-dependent and -independent manner.

Forced inhibition of $N F-\kappa B$ signaling has no visible inhibitory roles on parental T24/J82 cells. Our data indicated that inhibition of $\mathrm{NF}-\kappa \mathrm{B}$ signaling by PDTC in $\mathrm{T} 24^{\mathrm{R}} / \mathrm{J} 82^{\mathrm{R}}$ cells led to the attenuation of malignancy and reversal of EMT. In contrast, NF- $\kappa \mathrm{B}$ signaling was suppressed in parental $\mathrm{T} 24 /$ J82 cells. In parallel, as indicated in Fig. 5C and D, PDTC had no visible effect on the migration/invasion and proliferation of parental T24/J82.

\section{Discussion}

Chemoresistance, especially acquired chemoresistance, is considered a vital obstacle in the battle against cancer and can lead to the failure of cancer therapy $(20,31)$. Chemotherapy, in accordance with radiotherapy, is the final regimen for BCa patients. In addition, in both neoadjuvant chemotherapy and traditional chemotherapy for $\mathrm{BCa}$, cisplatin is the one irreplaceable reagent. Thus, cisplatin resistance ubiquitously appears in $\mathrm{BCa}$ patients receiving chemotherapy, which is why it is important to investigate this mechanism further as done in recent decades. To dissect this mechanism, the present study was performed.

First, we used cisplatin treatment to obtain chemoresistant cell lines as described in the Materials and methods. Our results suggested that we efficiently obtained the stable cisplatin-resistant cell lines $\mathrm{T} 24^{\mathrm{R}} / \mathrm{J} 82^{\mathrm{R}}$ (Fig. 1A). In addition, in accordance with our hypothesis, these $\mathrm{T} 24^{\mathrm{R}} /$ $\mathrm{J} 82^{\mathrm{R}}$ cells manifested enhanced wound healing (Fig. 1B), proliferation (Fig. 1C) and migration/invasion (Fig. 1E) capacity. NF- $\kappa$ B signaling was activated in these $T 24^{\mathrm{R}} / \mathrm{J} 82^{\mathrm{R}}$ cells (Fig. 2B), accompanied by the process of EMT (Fig. 2A) and elevated expression of ABCB1 (Fig. 1C). Although our unpublished data partially revealed the mechanism responsible for cisplatin-induced chemoresistance, much work remains to be done.

Silibinin, a polyphenolic flavonoid component isolated from the fruits or seeds of milk thistle (Silybum marianum), has been clinically used to treat various liver diseases and has been marketed as a dietary supplement (32). Our previous results indicate that silibinin suppressed $\mathrm{BCa}$ by acting on tumor cell mitochondria (18) or another mechanism (33). Therefore, we hypothesized that silibinin might play important roles in the process of EMT, which has been previously reported in other tumors $(28,29)$. Our results indicate that silibinin significantly suppresses the nuclear translocation of $N F-\kappa B$, inhibiting NF- $\kappa \mathrm{B}$ signaling (Fig. 3D). In accordance with our hypothesis, this inhibition is accompanied by an attenuated proliferation capacity (Fig. 3B) and migration/invasion capacity (Fig. 3C and E) and the reversal of EMT (Fig. 4A and B). The process by which silibinin inhibits the NF- $\kappa \mathrm{B}$ signal is still unknown, but this result indicates that silibinin can potentially be used in BCa therapy.

As indicated by our data, silibinin inhibits the malignancy of $\mathrm{BCa}$ cells in a dose-dependent manner, e.g., the concentration of silibinin ranged from 100 to $400 \mu \mathrm{M}$, accompanied by decreased expression of EMT-related markers and ABCB1 (Fig. 4). Silibinin protects against heart disease in older patients and is used as a key ingredient in a Chinese herbal formula for managing age-related disease, which is also effective in a dose-dependent manner. Thus, silibinin is suitable for older BCa patients, especially those with heart disease.

Compared with PDTC, which is a specific inhibitor of $\mathrm{NF}-\kappa \mathrm{B}$ signaling, silibinin manifests more powerful inhibitory roles that affect $\mathrm{BCa}$ cells, especially parental T24/J82 cells (Figs. 4D and 5A-D). This indicates that the inhibitory roles of silibinin acting upon parental BCa cells might be independent of NF- $\kappa \mathrm{B}$ signaling, with silibinin inhibiting the malignancy of $\mathrm{BCa}$ cells in a more ubiquitous manner. Taken together, these results lead us to conclude that silibinin suppresses BCa cell malignancy in an NF- $\kappa \mathrm{B}$-dependent and -independent manner.

In conclusion, as indicated in Fig. 5E, cisplatin treatment activates the NF- $\kappa \mathrm{B}$ signaling pathway in an unknown manner, leading to the enhanced malignancy of $\mathrm{BCa}$ cells, which can be inhibited by PDTC. However, silibinin inhibited $\mathrm{BCa}$ progression not only by suppressing $\mathrm{NF}-\kappa \mathrm{B}$ signaling but also via other mechanisms, resulting in an enhanced therapeutic effect for BCa patients. Although the exact mechanisms are still unknown, silibinin exhibits numerous benefits and could be incorporated into various forms of therapy for BCa patients. 


\section{Acknowledgements}

This study was supported in part by Overall Innovation Projects of Scientific and Technological Resources of Shaanxi Province (no. 2013KTCL03-04 to Yonggang Xu) and the National Natural Science Foundation of China (NSFC no. 81172436 to Sun Yi).

\section{References}

1. Skeldon SC and Larry Goldenberg S: Bladder cancer: A portal into men's health. Urol Oncol 33: 40-44, 2015.

2. Malats N and Real FX: Epidemiology of bladder cancer. Hematol Oncol Clin North Am 29: 177-189, vii, 2015.

3. Pang KH and Catto JWF: Bladder cancer. Surgery 31: 523-529, 2013.

4. Turo R, Cross W and Whelan P: Bladder cancer. Medicine 40: 14-19, 2012.

5. Kaufman DS, Shipley WU and Feldman AS: Bladder cancer. Lancet 374: 239-249, 2009.

6. Bellmunt J, Orsola A, Leow JJ, Wiegel T, De Santis M and Horwich A; ESMO Guidelines Working Group: Bladder cancer: ESMO Practice Guidelines for diagnosis, treatment and follow-up. Ann Oncol 25 (Suppl 3): iii40-iii48, 2014.

7. Sternberg CN, Bellmunt J, Sonpavde G, Siefker-Radtke AO, Stadler WM, Bajorin DF, Dreicer R, George DJ, Milowsky MI, Theodorescu D, et al; International Consultation on Urologic Disease-European Association of Urology Consultation on Bladder Cancer 2012: ICUD-EAU International Consultation on Bladder Cancer 2012: Chemotherapy for urothelial carcinoma neoadjuvant and adjuvant settings. Eur Urol 63: 58-66, 2013.

8. Neoadjuvant chemotherapy in invasive bladder cancer: Update of a systematic review and meta-analysis of individual patient data advanced bladder cancer (ABC) meta-analysis collaboration. Eur Urol 48: 202-205; discussion 205-206, 2005.

9. Julien S, Puig I, Caretti E, Bonaventure J, Nelles L, van Roy F, Dargemont C, de Herreros AG, Bellacosa A and Larue L: Activation of NF-kappaB by Akt upregulates Snail expression and induces epithelium mesenchyme transition. Oncogene 26: 7445-7456, 2007.

10. Saxena M, Stephens MA, Pathak $H$ and Rangarajan A: Transcription factors that mediate epithelial-mesenchymal transition lead to multidrug resistance by upregulating $\mathrm{ABC}$ transporters. Cell Death Dis 2: e179, 2011.

11. Kumar R, Deep G and Agarwal R: An overview of ultraviolet $B$ radiation-induced skin cancer chemoprevention by silibinin. Curr Pharmacol Rep 1: 206-215, 2015.

12. Li F, Ma Z, Guan Z, Chen Y, Wu K, Guo P, Wang X, He D and Zeng J: Autophagy induction by silibinin positively contributes to its anti-metastatic capacity via AMPK/mTOR pathway in renal cell carcinoma. Int J Mol Sci 16: 8415-8429, 2015.

13. Gu HR, Park SC, Choi SJ, Lee JC, Kim YC, Han CJ, Kim J, Yang KY, Kim YJ, Noh GY, et al: Combined treatment with silibinin and either sorafenib or gefitinib enhances their growthinhibiting effects in hepatocellular carcinoma cells. Clin Mol Hepatol 21: 49-59, 2015.

14. Pirouzpanah MB, Sabzichi M, Pirouzpanah S, Chavoshi H and Samadi N: Silibilin-induces apoptosis in breast cancer cells by modulating p53, p21, Bak and Bcl-XL pathways. Asian Pac J Cancer Prev 16: 2087-2092, 2015.

15. Bosch-Barrera J and Menendez JA: Silibinin and STAT3: A natural way of targeting transcription factors for cancer therapy. Cancer Treat Rev 41: 540-546, 2015.
16. Prajapati V, Kale RK and Singh RP: Silibinin combination with arsenic strongly inhibits survival and invasiveness of human prostate carcinoma cells. Nutr Cancer 67: 647-658, 2015.

17. Jiang K, Wang W, Jin X, Wang Z, Ji Z and Meng G: Silibinin, a natural flavonoid, induces autophagy via ROS-dependent mitochondrial dysfunction and loss of ATP involving BNIP3 in human MCF7 breast cancer cells. Oncol Rep 33: 2711-2718, 2015.

18. Zeng J, Sun Y, Wu K, Li L, Zhang G, Yang Z, Wang Z, Zhang D, Xue Y, Chen Y, et al: Chemopreventive and chemotherapeutic effects of intravesical silibinin against bladder cancer by acting on mitochondria. Mol Cancer Ther 10: 104-116, 2011.

19. Hayakawa M, Miyashita H, Sakamoto I, Kitagawa M, Tanaka H, Yasuda $\mathrm{H}$, Karin $M$ and Kikugawa K: Evidence that reactive oxygen species do not mediate NF-kappaB activation. EMBO J 22: 3356-3366, 2003.

20. Housman G, Byler S, Heerboth S, Lapinska K, Longacre M, Snyder N and Sarkar S: Drug resistance in cancer: An overview. Cancers (Basel) 6: 1769-1792, 2014.

21. Herr HW, Dotan Z, Donat SM and Bajorin DF: Defining optimal therapy for muscle invasive bladder cancer. J Urol 177: 437-443, 2007.

22. Li F, Zhang J, Arfuso F, Chinnathambi A, Zayed ME, Alharbi SA, Kumar AP, Ahn KS and Sethi G: NF- $\kappa$ B in cancer therapy. Arch Toxicol 89: 711-731, 2015.

23. Gilmore TD and Wolenski FS: NF-кB: Where did it come from and why? Immunol Rev 246: 14-35, 2012.

24. Sui H, Zhu L, Deng W and Li Q: Epithelial-mesenchymal transition and drug resistance: Role, molecular mechanisms, and therapeutic strategies. Oncol Res Treat 37: 584-589, 2014.

25. Jung HJ, Park JW, Lee JS, Lee SR, Jang BC, Suh SI, Suh MH and Baek WK: Silibinin inhibits expression of HIF-1 $\alpha$ through suppression of protein translation in prostate cancer cells. Biochem Biophys Res Commun 390: 71-76, 2009.

26. Kim S, Choi JH, Lim HI, Lee SK, Kim WW, Kim JS, Kim JH, Choe JH, Yang JH, Nam SJ, et al: Silibinin prevents TPA-induced MMP-9 expression and VEGF secretion by inactivation of the Raf/MEK/ERK pathway in MCF-7 human breast cancer cells. Phytomedicine 6: 573-580, 2009.

27. Kim S, Kim SH, Hur SM, Lee SK, Kim WW, Kim JS, Kim JH Choe JH, Nam SJ, Lee JE, et al: Silibinin prevents TPA-induced MMP-9 expression by down-regulation of COX-2 in human breast cancer cells. J Ethnopharmacol 126: 252-257, 2009.

28. Wu K, Zeng J, Li L, Fan J, Zhang D, Xue Y, Zhu G, Yang L, Wang $X$ and He D: Silibinin reverses epithelial-to-mesenchymal transition in metastatic prostate cancer cells by targeting transcription factors. Oncol Rep 23: 1545-1552, 2010.

29. Cufí S, Bonavia R, Vazquez-Martin A, Oliveras-Ferraros C, Corominas-Faja $\mathrm{B}$, Cuyàs $\mathrm{E}$, Martin-Castillo $\mathrm{B}$, Barrajón-Catalán E, Visa J, Segura-Carretero A, et al: Silibinin suppresses EMT-driven erlotinib resistance by reversing the high miR-21/low miR-200c signature in vivo. Sci Rep 3: 2459, 2013.

30. Sun SC: The noncanonical NF- $\kappa$ B pathway. Immunol Rev 246: 125-140, 2012.

31. Anreddy N, Gupta P, Kathawala RJ, Patel A, Wurpel JN and Chen ZS: Tyrosine kinase inhibitors as reversal agents for ABC transporter mediated drug resistance. Molecules 19: 13848-13877, 2014.

32. Wellington $\mathrm{K}$ and Jarvis B: Silymarin: A review of its clinical properties in the management of hepatic disorders. BioDrugs 15: 465-489, 2001

33. Li L, Gao Y, Zhang L, Zeng J, He D and Sun Y: Silibinin inhibits cell growth and induces apoptosis by caspase activation, downregulating survivin and blocking EGFR-ERK activation in renal cell carcinoma. Cancer Lett 272: 61-69, 2008. 